\title{
Design and Realization of MapSUV Rural Land Surveying Palm Mapping System
}

\author{
Yonghua WANG, Wenfen LUO, Wenyou FAN \\ GIS project research center of Ministry of Education
}

\begin{abstract}
The original surveying tools and methods are backward and low efficient and they will also generate lots of errors in the National secondary land surveying. MapSUV rural land surveying palm mapping system (MapSUV palm mapping system) based on 3S techniques, combines MapGIS rural land surveying database management system. It supports the spatial location information collection and attributes data entry. By combining with GPS receiver, it ensures high accuracy in small volume, which greatly facilitates land surveying. This paper main researched system structure, function module design and key techniques.

It introduced the practical process of map spot attribute checking and map spot boundary. Then it gave the application assessment. The results shows that this system greatly improves the work efficiency of outdoor surveying and shorten the time of land surveying, database build and updating.
\end{abstract}

Keywords: secondary land surveying; palm mapping; MapSUV

\section{MAPSUV 農村土地調查掌上測圖系統的設計與實現}

\author{
王勇華，羅文芬，樊文有 \\ 教育部 GIS 工程研究中心，湖北 武漢
}

\begin{abstract}
摘 要: 傳統的測量工具和調查方法, 效率低下, 誤差較大。MAPSUV 農村土地調查掌上測圖系統 ( 以 下簡稱 MAPSUV 掌上測圖系統）基於 3S 技術結合 MapGIS 農村土地調查資料庫管理系統，實現空間 位置資訊的採集和屬性資訊的錄入; 配合先進的 GPS 接收機，精度高，體積小，用於土地調查可以提 高效率。本文對 MAPSUV 掌上測圖系統的系統結構設計、功能模組設計、閣鍵技術做了詳細的探討, 介紹了利用該系統進行圖斑屬性核查以及圖斑界線調查的實施流程，最後給出應用評價。利用該系統 進行土地調查，可以有效地提高外業調查的工作效率，同時縮短土地調查資料建庫和更新的時間週期。
\end{abstract}

關鍵字: 第二次國土大調查; 掌上測圖; MAPSUV

\section{1. 引 言}

根據《地籍管理“十一五”發展規劃綱要》, 我國 將在 2010 年前開展第二次全國土地調查。在以往的
土地變更調查中, 我國基本上採取傳統的測量工具和 手段, 調查方法和技術手段落後, 效率低下, 誤差較 大，加之近 10 年來土地利用現狀的劇烈變化，難以 保證國土資源管理對現勢性好、精度高的土地利用現 
狀資料的需要。面對即將開展的二次全國土地調查, 這一現狀不容樂觀。因此我國急需結合 $3 S$ 技術, 移 動性能好的測圖軟體。

MAPSUV 掌上測圖系統是一個外業調查軟體, 支援全站儀和 GPS 資料錄入，實現了座標、圖形、 屬性資料的同步採集、現場成圖，將測量的大部分工 作在外業中完成, 使得野外測繪資料獲取及成圖一體 化。

MAPSUV 掌上測圖系統結合農村土地調查資料 庫管理系統, 為農村土地調查的外業核查與更新工作 提供了一種新方法。

\section{2. 系統設計}

整個系統的核心是資料獲取, 應滿足如下基本要 求: 能達到當前土地利用現狀調查所需的基本精度; 具有快速的野外資料獲取功能; 不僅能記錄點位元資 訊, 還應具有 GIS 的功能, 如顯示圖形, 記錄變更圖 斑物件, 保持 GPS 點與圖形的拓撲關係, 保持變更 圖斑物件的圖形和屬性關係; 具有較好的准即時資料 處理能力, 從而能夠準確及時反映土地利用的變化; 具有較高的自動處理能力, 較少的人工干預, 能夠記 錄資料的變更過程，降低內業資料處理的複雜程度; 系統記錄的資料格式和處理流程能夠滿足當前變更調 查工作的有關技術規範。資料獲取完成後, 需要對處 理完的資料進行資料上載處理, 我們採用 MAPGIS 農 村土地調查管理系統完成。

\section{1 系統邏輯結構設計}

根據第二次全國土地調查相關檔, 在農村土地調

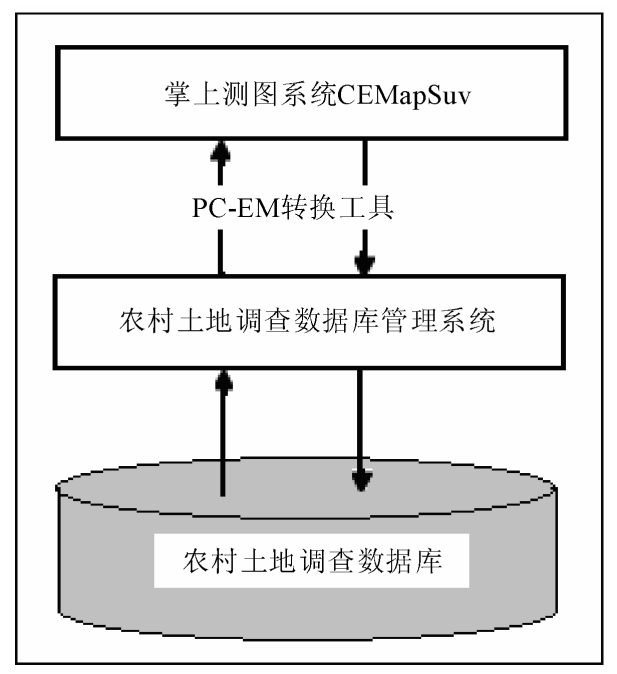

圖 1. CeMapSuv 與農村土地調查系統邏輯關係圖

查外業處理過程中, 要求掌上測圖系統能導入影像圖 作為底圖, 進行點線編輯, 圖層的管理等, 以及即時 定位功能。掌上測圖系統與農村土地調查系統之間的 關係圖如圖 1 。

系統由 PDA 端嵌入式 GIS 和桌面伺服器軟體構 成, PDA 端負責 GPS 信號接收和其他 GIS 操作, PC 端負責地圖資料準備, 地圖資料後期處理、USB 介面 和串口連接。PDA 與 PC 功能示意圖如圖 2。

\section{2 系統功能模組設計}

功能模組是系統功能的執行單元, 彼此之間相對 獨立, 合理的模組劃分有助於實現系統針對不同應用 的功能裁剪。系統結構設計如下圖 3。

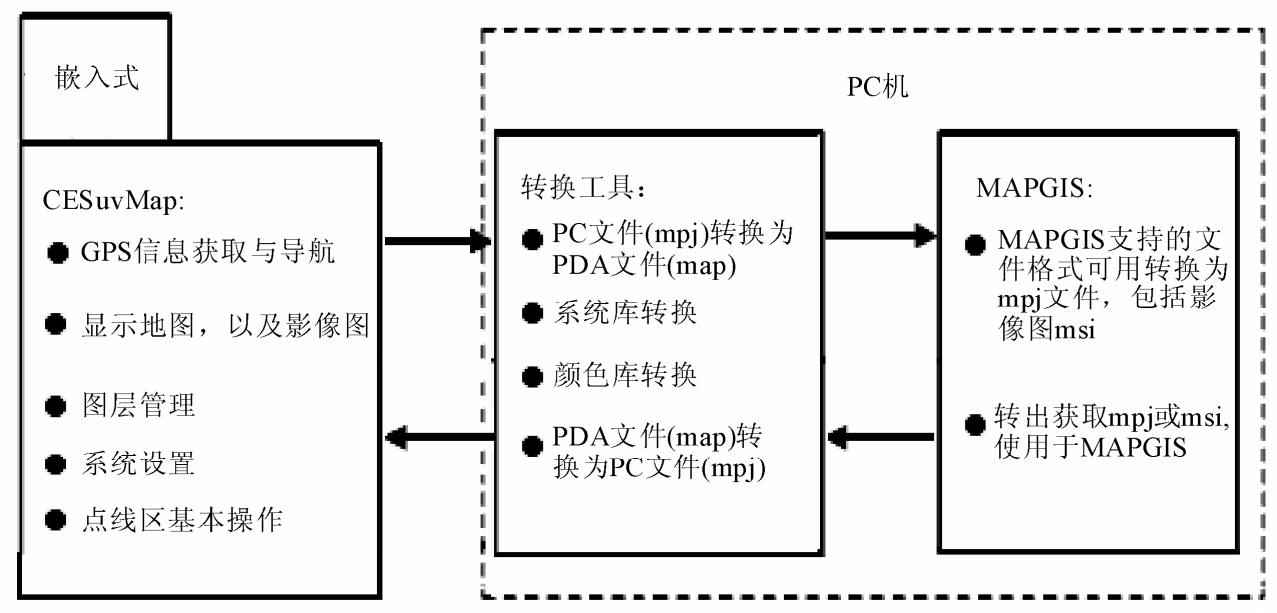

圖 2. PDA 與 PC 功能示意圖 


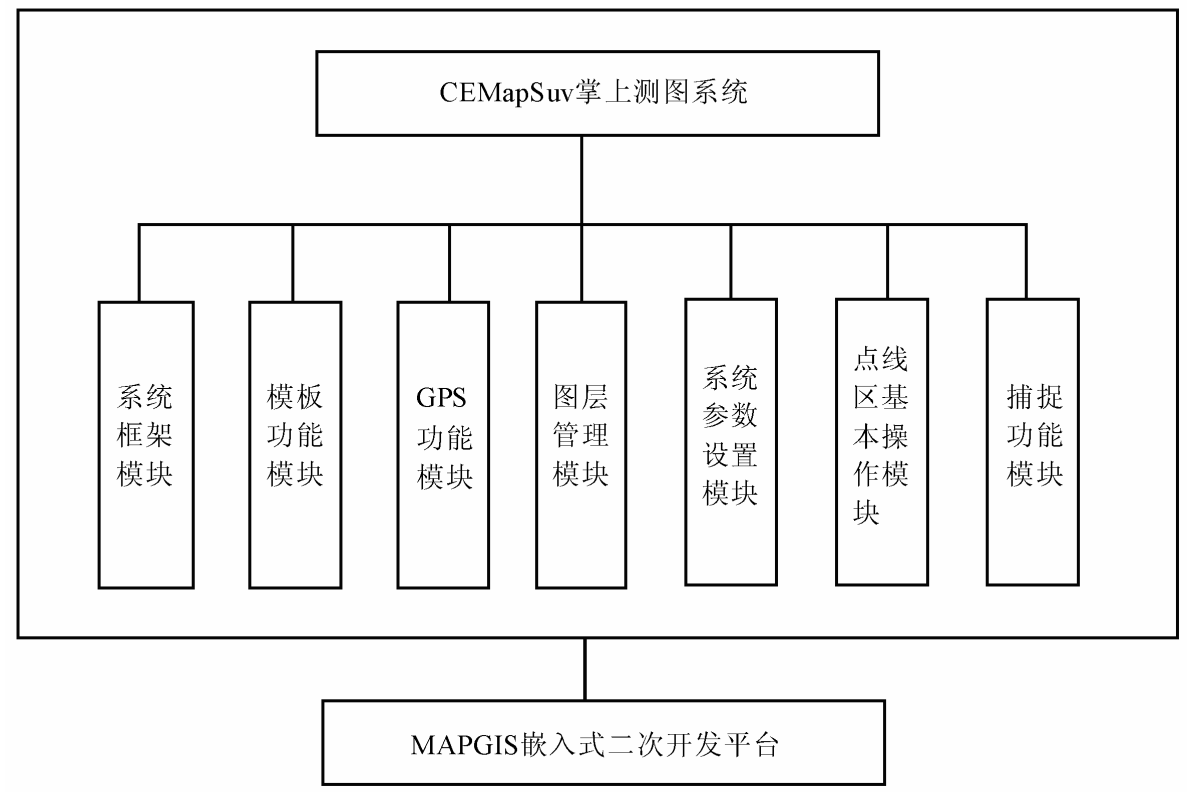

圖 3. 系統功能圖

\section{3 關鍵技術問題處理}

\subsection{1 海量資料處理}

面對大量的二調圖形資料, PDA 的處理速率和 存儲性能都是有限的, 如果把整個省的二調資料直接 導入到一個 PDA 終端中, 目前是不可能的。通過切 割技術實現海量資料處理, 在內業工程中, 根據行政 劃分省到市縣, 進行掌上測圖系統的向量編輯及外業 採集。

\subsection{2 地圖匹配}

實現 PC 地圖載入 PDA 的過程, 一般情況需要考 慮土地調查過程中的地圖參數匹配問題, 我國目前常 用兩個國家大地坐標系，即 1980 年國家大地坐標系 （C80）和 1954 年北京坐標系（舊 BJ-54）。兩者都 是參心大地坐標系統。通過全球衛星定位 (GPS) 獲 取的座標使用的是 WGS-84 坐標系。在系統中提供了 兩種解決方案。

1)通過採集控制點和地圖的誤差校正, 把地圖 轉換為基於 WGS84 的地圖。實現了地圖的全部平 移, 並且還需要地圖的反平移, 消耗代價比較大, 但可以解決没有控制點無法獲取七參數的前提下使 用。

2)通過已有的國家控制點, 獲取七參數, 在系統 設置中進行七參數設置。系統提供 WGS-84 向 C80 和 BJ-54 的轉換, 只需要設置七參數或者輸入控制點, 就可以將 GPS 上獲取的點進行轉換。

\subsection{3 轉換工具}

MAPGIS 的地圖一般都是基於 PC, 直接載入 PDA 中是無法識別的, 反之亦然, 需要進行相關的 地圖轉換。MAPGIS 的農村土地調查系統提供了嵌入 式轉換工具, 是 PC 機地圖與 PDA 地圖的連接橋樑。 嵌入式轉換工具對地圖資料進行壓縮處理並建立新資 料庫, 在 PDA 資源有限的前提下, 提高了 PDA 中的 使用效率。其他地圖資料 ( *.DWG 等) 經過預處理 後, 轉換為 MAPGIS 提供的資料(*.MPJ), 可以轉換 為掌上測圖的資料。

\section{3. 實施方案}

從 MapGIS 縣級農村土地調查資料庫管理系統裁 一塊包含影像圖的 MPJ 工程為底圖, 實現該區域地 物的核查工作, 即 GPS 自動定位到相應地塊, 即時 顯示圖斑資訊, 核查地塊是否發生變化, 如果發生變 化則修改相應圖斑資訊。其資料流程圖如下圖 4。

\section{1 載入地圖}

通過行政區劃分裁剪總圖獲得以縣級為單位的小 店裁剪圖, 獲取了一個 MPJ 工程, 再進行地圖匹 配，獲取控制點，通過MAPGIS 軟體的投影變換功能 獲取七參數, 製作七參數 TXT 檔備用。在轉換工具 EMXConverter.exe 中打開, 〈地圖轉換〉 - 〈轉成 CE 
檔〉後, 得到 MAP 檔。通過微軟提供的 ActiveSync 軟體, 把掌上資料拷入掌上機中。內業工作完成, 可 以攜帶PDA 進行外業工作。地圖裁剪處理如下圖 5。

\section{2 地圖編輯}

通過PDA 廠商提供的 GPS 介面搜索工具, 獲取 當地的 GPS 串口和串列傳輸速率。在掌上測圖系統 中打開地圖, 進行系統設置, 坐標系為: 大地坐標系 -WGS84, GPS 設置為：串口（com1）-井列傳輸速率 (9600), 載入七參數文件。啟動掌上測圖的 GPS 功 能, 觀察狀態欄上衛星的數量, 可以開始採集導航, 核查圖斑資訊並修改。記錄 GPS 點的位置資訊。進 行權屬界線、地類圖斑界線、線狀地物的採集或者核 查以及屬性資料的採集或者核查。裁剪 PDA 地圖, 地類圖斑核查與編輯如下圖 6, 7。

\section{3 成果導出}

把從掌上獲取的資料 (總共 5 個檔) 拷到 PC 機 中, 通過轉換工具 EMXConverter.exe, <地圖轉換>-< 轉成 PC 檔 $>$, 即可獲得 MAPGIS 的點線區文件。通 過 MAPGIS 系列軟體可以轉換成任意其他格式的檔。

\section{4 精度分析}

在 MAPSUV 掌上測圖系統的使用過程中, 由於 國土二次調查的圖都是 1: 1 萬的, 如果只是進行屬 性核查工作, 當導航點在 5 米左右的區域內(不需要 經過差分), 認為是有效值, 導航功能的精度基本滿 足要求導航的功能。使用時, GPS 點到達相應圖斑, GPS 點取圖斑功能運行正常。圖形資料與影像圖的向 量疊加, 以及導入導出操作簡潔易操作, 這個時候市

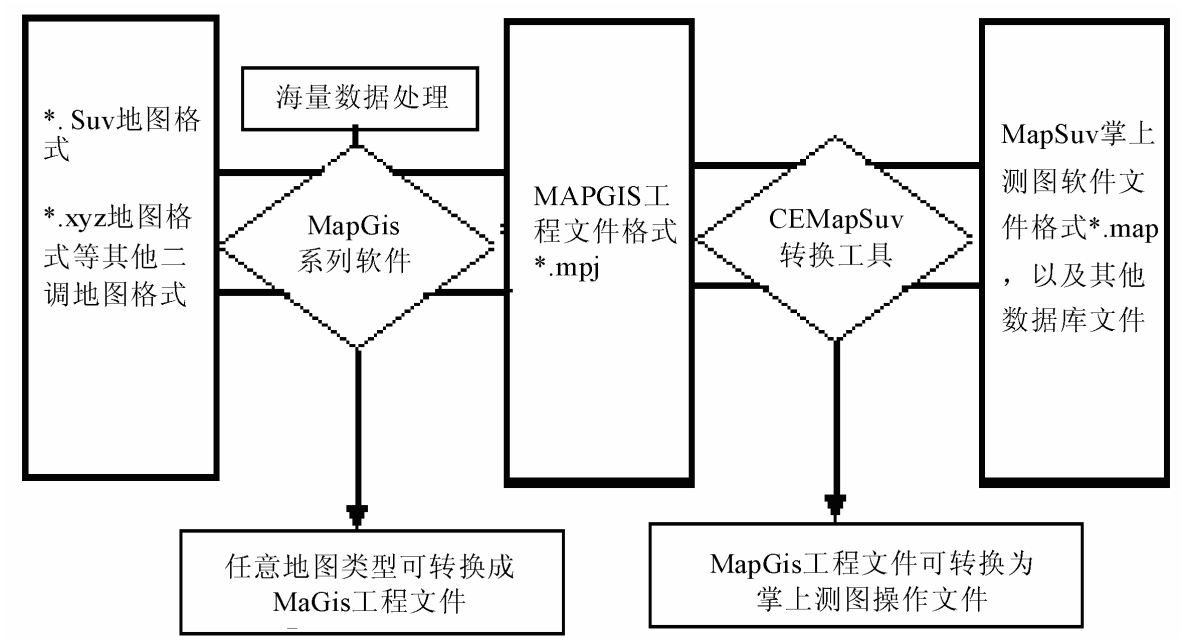

圖 4. 圖形資料流程圖

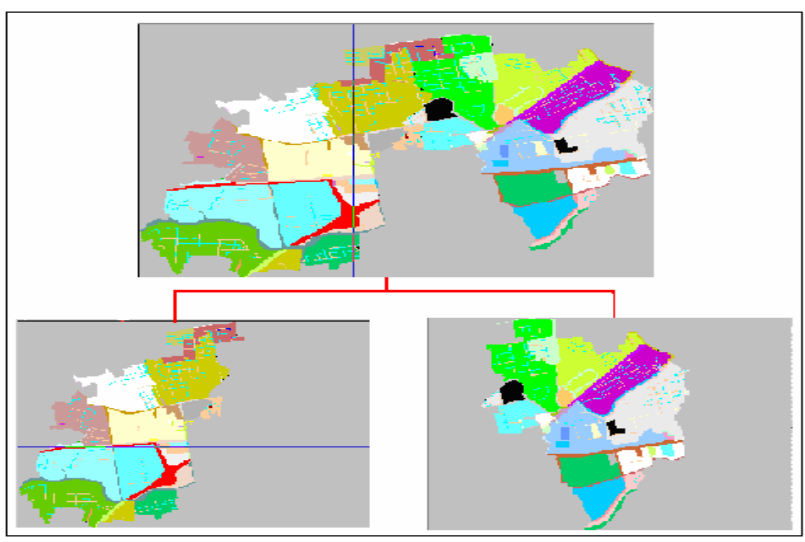

圖 5. 地圖裁剪處理 


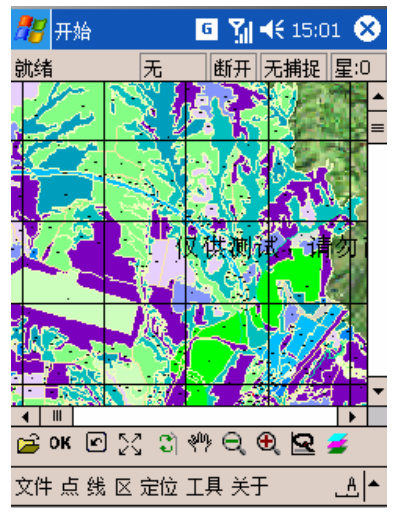

圖 6. 裁剪 PDA 地圖

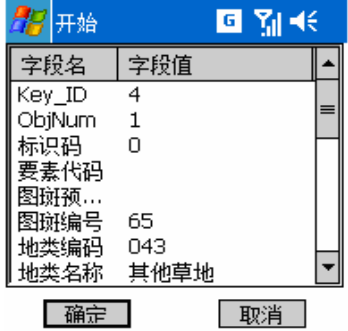

圖 7. 地類圖斑核查與編輯

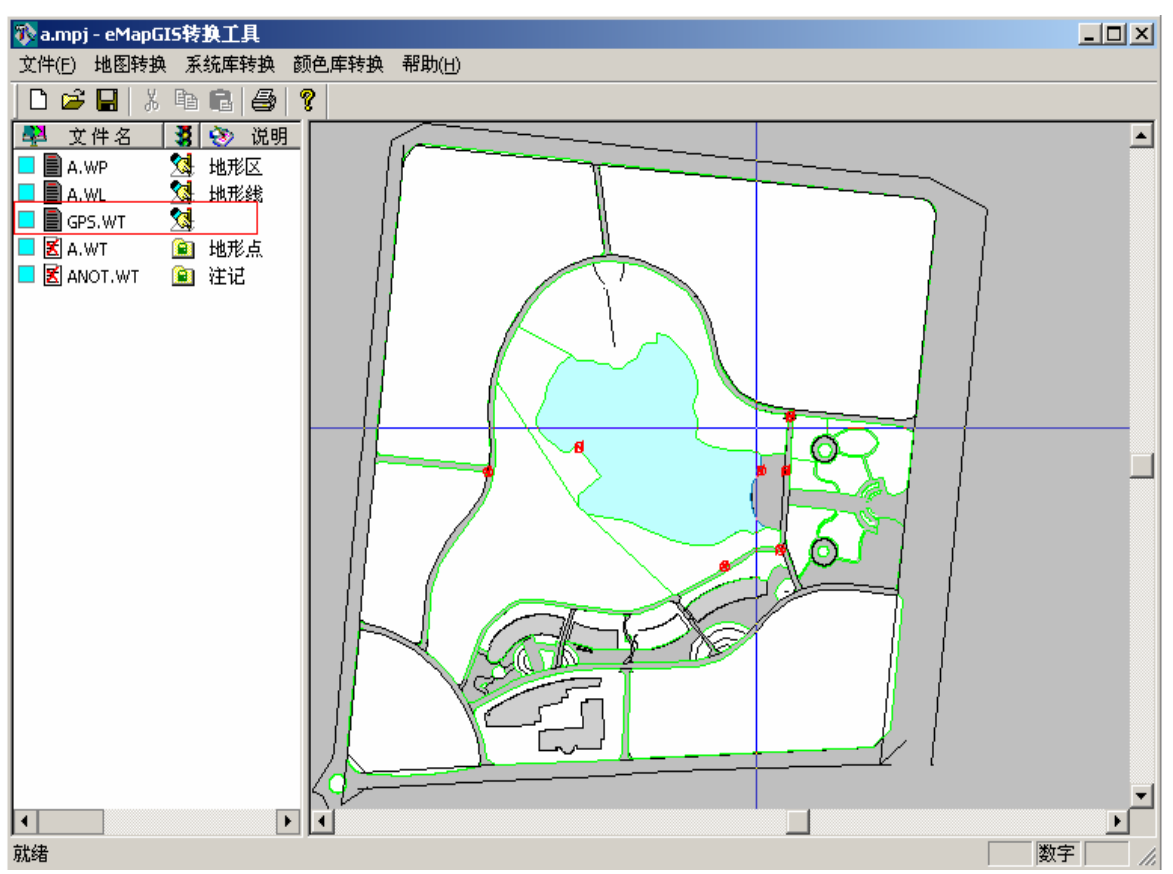

圖 8. 獲取 GPS 點資訊後 PC 地圖

面上一般的精度在十米以內的 GPS 設備都可以滿足 需求。如果要採集座標點進行量測, 則需要精度在亞 米級以內的 GPS 設備。獲取 GPS 點資訊後 PC 地圖如 上圖 8 。

\section{4. 應用評價}

MAPSUV 掌上測圖系統能有效的應用於土地調 查, 它融合了 GIS/GPS/RS 技術、專業化的外業資料 獲取模組和內業資料處理工具。在系統開發設計的過 程中, 按照“外業採集、內業處理及建庫一體化管理” 的原則, 實現了 $3 \mathrm{~S}$ 集成的手持外業調查設備, 極大 地提高了外業調查的工作效率, 同時縮短了土地調查 資料匯總和資料建庫的時間週期。MAPSUV 掌上測 圖系統是土地調查技術的一次革新。
1)利用先進的廣域差分技術, 對於農村土地調查 無需基準站, 單機單人作業即可獲取亞米級定位。具 有海量、高效的資料管理能力, 能夠實現土地利用向 量資料的高效管理與編輯, 以及向量地圖與影像底圖 向量疊加顯示。一般一個縣的地圖資料載入，也可以 有更小的行政劃分，如：村、組等。

2)MAPSUV 掌上測圖系統操作簡單，人員容易 培訓, 非常適合基層(縣級、鄉鎮)土地管理人員使 用。該系統實現了野外調查手段和方法的“俊瓜”式操 作，只要基層土地管理人員手持 GPS-PDA，在現場 調查時“走到看到測到”。GPS 主機採用一鍵式，只要 打開電源開關，GPS 即可工作。PDA 的操作全部功 能表化, 只要按照介面提示一步步操作, 就可以完成 複雜的定位及屬性錄入工作。有了 PDA 所記錄的位 
置資訊和屬性資訊, 處理人員在室內即可完成變更調 查的所有工作, 這一切對於缺乏專業技能訓練的基層 人員來說，技術優勢顯而易見。

3)調查過程、調查結果全數位化，工作效率大為 提高。和以往的土地調查方法相比, “CEMapSuv”採 用了全新的調查手段，以往皮尺量邊距的定位模式變 為 GPS 的自動定位、現場在 PDA 上錄入相關的屬性 資訊後, 完成全數位化的野外調查的資訊採集與記 錄。在土地變更調查過程變得方便、可靠、實用的同 時, 調查成果實現了數位化、作業流程規範化, 真正 做到“圖件、資料、實地”三者一致。

\section{5. 總 結}

在國土二次調查中, 調查人員現場調查時,同時 有了 GPS、RS、GIS 三樣東西,就可以將空間位置資 訊的採集、屬性資訊的錄入有機結合起來。手持小巧 的 GPS 接收機, 在測量地塊的各個拐點上分別站立 5 秒鐘，顯示幕上即直觀地顯示出地塊的圖斑，按照螢 幕提示的功能表化介面依次選擇或錄入, 該地塊的位 置資訊和屬性資訊等資料即被有效採集。
該項技術成果具有廣闊的應用前景,它不僅適用 於土地變更調查,同樣適用於農村權屬調查和勘測定 界、基本農田保護檢查、新增建設用地勘測定界、規 劃實施檢查、農村土地整理驗收等,尤其在土地執法 監察領域,其特殊效力更不可小覻。

\section{參考文獻 (References)}

[1] 武漢中地數碼有限公司. 嵌入式 GIS 開發手冊. 2002,8.

[2] 武漢中地數碼有限公司. CEMapSuv 使用文檔. 2008,4.

[3] 汪兵, 李存斌, 陳鵬等. EVC 高級編程及其應用開發. 中國水利水電出版社, 2005.

[4] 北京合眾思狀有限公司. E718 二次開發文檔. 2006, 11.

[5] 北京天恒昕業科技發展有限公司產品宣傳手冊.

[6] 二次調查技術規程 2007,09,07.

[7] 傅中君. 基於 ARM 的 PDA 軟硬體平臺設計[A]. 南京 理工大學，2006, 06.

[8] 劉庚. 基於 PDA 的個人導航系統的研究與應用 [A]. 大 連理工大學，2006, 12.

[9] 史先琳. 基於 PDA 的移動 GIS 的研究與設計[A]. 四川 大學，2006, 05.

[10] 張俊寧. 基於 PDA 的移動導航資源系統的設計與實現 [A]. 大連理工大學, 2006, 11. 

